УДК 82

DOI: $10.21779 / 2542-0313-2017-32-4-27-33$

\title{
А.Н. Горбанева
}

\section{Эпилог как финал романа Ф.М. Достоевского «Преступление и наказание»}

Дагестанский государственный университет; Россия, 367001, г. Махачкала, ул. М. Гаджиева, 43a; gorbaneva69@mail.ru

В статье рассматриваются место и значение эпилога в идейной структуре романа Ф.М. Достоевского «Преступление и наказание». Выявляются две его основные функции.

В эпилоге «Преступления и наказания» две главы, первая из которых выполняет традиционную функцию послесловия, а вторая - функцию финала, завершения идейного сюжета романа. В этом плане эпилог связан с центральной проблемой произведения: после преступления и наказания происходит воскрешение героя, последствия которого отнесены автором в будущее, за пределы повествования, что делает финал открытым.

В процессе работы над романом Достоевским были оставлены без реализации другие варианты финала (самоубийство Раскольникова, «видение Христа» герою, раскаяние после пожара). В окончательной редакции финал в полной мере соответствовал сокровенному замыслу писателя: показать духовное воскресение героя.

В эпилоге оно происходит «вдруг», как чудо, но выглядит художественно убедительным, ибо тщательно подготовлено всем предшествующим текстом произведения.

Ключевые слова: Достоевский, роман, идейная структура, эпилог, финал.

«Эпилог» - так назвал Достоевский две последние главы романа «Преступление и наказание». Однако по своей функции в содержательно-художественной структуре романа главы эти являются не только эпилогом, но и финалом произведения.

По своему прямому смыслу и назначению эпилог (от греч. еpi - после и $\log o s-$ слово, буквально - послесловие) - это изображение событий и дальнейших судеб героев после завершения, развязки основного конфликта и главных событий.

Финал же (от итал. finale - конец) - это конец произведения, развязывающий и разрешающий его конфликт, имеющий итоговый характер и смысл.

С этой точки зрения, две последние главы «Преступления и наказания» - это не только послесловие, но и последнее итоговое слово романа, его подлинный финал. Это своеобразие эпилога романа Достоевского, его двуединая функция как послесловия и последнего слова отчетливо видны при сравнении с традиционным эпилогом романа И.С. Тургенева «Отцы и дети». В тургеневском романе финал - смерть главного героя Базарова, а эпилог - заключительная XXVIII глава, в которой кратко и сжато рассказывается о жизни и судьбах всех остальных героев романа спустя полгода после трагической развязки.

В одной из редакций «Преступления и наказания» намечался финал, подобный тому, какой мы находим в тургеневском романе. «Финал романа» - так назван Достоевским один из фрагментов произведения, который открывается словами: «Раскольников застрелиться идет» (подстрекаемый Свидригайловым: «Застрелитесь, не с вашим характером оставаться в живых, вам два пути: или сознаться, или застрелиться» [1, т. 7, с. 204]. В последней редакции Раскольников выбирает первый путь и признается: «Это я убил тогда старуху-процентщицу и сестру ее Лизавету топором и ограбил» [1, т. 6, с. 410]. 
Вариант финала романа с самоубийством Раскольникова был исключен для Достоевского, поскольку он не отвечал глубинному замыслу произведения - художественно исследовать события не только преступления и наказания, но и воскресения героя.

Об этом замысле, оставшемся неизменным на всем протяжении работы над романом, Достоевский сообщал еще в сентябре 1865 года в письме к М.Н. Каткову, редактору «Русского вестника», которому он предлагал начатую в Висбадене повесть: геройстудент совершает свое «предприятие скоро и удачно», на него нет никаких подозрений, «но тут-то и разворачивается весь психологический процесс преступления, неразрешимые вопросы восстают перед убийцею, неподозреваемые и неожиданные чувства мучают его сердце. Божья правда, земной закон берут свое, и он кончает тем, что принужден сам на себя донести. Принужден, чтоб хотя погибнуть в каторге, но примкнуть опять к людям; чувство разомкнутости, разъединенности с человечеством, которое он ощутил тотчас же по совершении преступления, замучило его. Закон правды и человеческая природа взяли свое... Преступник сам решает принять муки, чтоб искупить свое дело. Впрочем, трудно мне вполне разъяснить мою мысль» [1, т. 28, с. 137].

Наибольшие трудности ожидали Достоевского как раз на пути поиска такого финала романа, который бы отвечал его исходящему замыслу.

«Финал романа стоил Достоевскому не меньше трудов, чем художественное решение проблемы мотивов преступления» [2, с. 149].

В подготовительных материалах к роману намечалось (помимо варианта с самоубийством Раскольникова) еще два возможных финала романа.

Первый - это тот, который обозначен Достоевским как «видение Христа» [2, т. 7 , c. 135]: именно оно должно было побудить Раскольникова к раскаянию.

Второй возможный финал романа, который более подробно рассматривался Достоевским в черновиках, - это пожар. Во время пожара, случившегося после убийства старухи-процентщицы, Раскольников спасает детей (при этом сам едва не погибает), и по возвращении домой признается в своем преступлении родным, а потом раскаивается и всенародно. За подвиг на пожаре и чистосердечное покаяние ему «по высочайшему повелению» сбавляют срок.

«Болен после пожара. Пожар решил все. Пожар, спасение. Ура! Есть жизнь». «Гордость и надменность его и самоуверенность в безвинности идут все crescendo, и вдруг на самом сильном фазисе, после пожара, он идет предать себя» [2, т. 7, с. 135, 143, 167].

В конце концов Достоевский оставил без реализации оба варианта развязки, в каждом из которых раскаяние Раскольникова происходило сразу после преступления. «Пожар», как и «видение Христа», - финал искусственный и антихудожественный» [2, c. 153], ибо и тот и другой упрощали сложнейшие проблемы преступления, наказания и раскаяния-воскресения и их художественное решение.

Наряду с этим в одной из черновых записей Достоевский намечал и такой, более сложный и реалистический финал: «Глава «Христос» (как «сон Обломова») кончается пожаром. После пожара он пришел к ней проститься. «Нет, я еще не готов, я полон гордости и фальши; я только что начинаю весь процесс переделки» - в каторге (7 лет каторги, смягчено по высочайшему повелению» [1, т. 7, с. 166]. Достоевский поведет своего героя по этому трудному пути и завершит художественное исследование «процесса переделки» Раскольникова в эпилоге, что будет отвечать первоначальному, неизменному и глубинному замыслу романа и его сокровенному смыслу.

«В самом деле, - спрашивает в одном из первых откликов на «Преступление и наказание» критик Страхов, - в чем главный интерес романа? Чего ждет постоянно читатель с той минуты, как совершено преступление? Он ждет внутреннего переворота в Раскольникове, ждет пробуждения в нем истинно человеческого образа чувств и мыслей. 
Тот принцип, который Раскольников хотел убить в себе самом, должен воскреснуть в его душе и заговорить еще с большею силою, чем прежде» [3, с. 122].

Внутренний переворот в Раскольникове, воскрешение в его душе нравственного принципа - что и является истинным финалом романа - происходят в эпилоге «Преступления и наказания».

В эпилоге две главы, идейно-художественные функции которых заметно различаются.

Первая глава по сути своей является «послесловием» криминального сюжета романа, который включает такие события, как убийство Раскольниковым старухипроцентщицы, напряженный поединок между героем и следователем Порфирием Петровичем, явка Раскольникова в полицейскую контору с повинной и признание его в совершенном преступлении (чем и заканчивается последняя глава последней, шестой части романа).

В первой главе эпилога мы узнаем о суде над Раскольниковым, информация о ходе и исходе которого завершает криминальный сюжет романа, а также о судьбах Дуни, Разумихина и матери Раскольникова, о первых месяцах пребывания в Сибири осужденного на каторгу Раскольникова и последовавшей за ним Сони.

Вторая глава эпилога выполняет функцию финала идейного сюжета романа, сердцевиной которой являются проблемы преступления, наказания и воскресения в их нравственно-религиозном содержании. Ее главным событием является духовное воскресение Раскольникова, которое и есть - по замыслу и смыслу романа - подлинный финал произведения. Ибо ни явка с повинной и признание, ни суд не разрешали главной коллизии в душе Раскольникова: он признался в совершенном преступлении и покаялся всенародно на Сенной площади, но не раскаялся в нем.

С констатации этого факта, собственно, и начинается вторая глава эпилога. Изображая духовное состояние охваченного тревогой и тяжкими размышлениями Раскольникова, Достоевский констатирует: «И хотя бы судьба послала ему раскаяние - жгучее раскаяние, разбивающее сердце, отгоняющее сон, такое раскаяние, от ужасных мук которого мерещится петля и омут! О, он бы обрадовался ему! Муки и слезы - это ведь тоже жизнь. Но он не раскаивался в своем преступлении <... $>$.

«Чем, чем, - думал он, - моя мысль была главнее других мыслей и теорий, роящихся и сталкивающихся одна с другой на свете, с тех пор, как этот свет стоит?..

Ну чем мой поступок кажется им так безобразен? - говорил он себе. - Тем, что он злодеяние? Что значит слово «злодеяние»? Совесть моя спокойна <...>.

Вот в чем одном признавал он свое преступление: только в том, что не вынес его и сделал явку с повинною» [6, с. 417].

Вся небольшая по объему, но емкая по содержанию вторая глава эпилога построена на разительном контрасте между этим духовным состоянием нераскаявшегося убийцы и заключительной сценой (и главы, и романа в целом), когда ранним утром на берегу реки происходит чудо духовного воскресения Раскольникова.

«Как это случилось, он и сам знал, но вдруг что-то как бы подхватило его и как бы бросило к ее ногам. Он плакал и обнимал ее колени. В первое мгновение она ужасно испугалась <...>. Но тотчас же, в тот же миг она все поняла. В глазах ее засветилось бесконечное счастье $<\ldots>$.

Они хотели было говорить, но не могли. Слезы стояли в их глазах. Они оба были бледны и худы, но в этих больных и бледных лицах уже сияла заря обновленного будущего, полного воскресения в новую жизнь. Их воскресила любовь...» [6, с. 421].

«Вместо диалектики наступила жизнь» [6, с. 422], и это положило начало процессу «перерождения убеждений» Раскольникова, открыло перед ним возможность другой 
жизни, о которой в последних строках романа сказано: «Он даже и не знал тогда, что новая жизнь не даром же ему достается, что ее надо еще дорого купить, заплатить за нее великим, будущим подвигом...» [6, с. 422].

Финал романа (вторая глава эпилога) завершает художественное исследование духовной драмы Раскольникова, завернутой в произведении, и остается открытым относительно дальнейшей судьбы героя.

Вопрос вопросов, возникавший в связи с финалом «Преступления и наказания» в критической и исследовательской литературе: насколько художественно убедительно мотивировано то, о чем Достоевский рассказывает на последних страницах романа.

Вопреки традиционному мнению о тенденциозности и слабой мотивированности финала романа, которое высказывали многие критики и исследователи (от Д. Мережковского до В. Шкловского) [4, с. 214; 5, с. 228], в работах последнего времени выдвигается и обосновывается противоположная точка зрения: воскресение Раскольникова в эпилоге только внешне выглядит внезапным чудом и совершается «вдруг», а на самом деле подготовлено всем действием романа.

Возможность переворота в душе человека - одно из важнейших убеждений Достоевского - мыслителя и художника. «Достоевский считает, что путь к добру и справедливости не заказан ни одному человеку, даже дурному, что в этом следует видеть нормальное явление, победу естественных чувств. Большое значение он придавал внезапности душевного переворота... Впечатление неожиданности происходящей перемены «вдруг» в значительной степени внешнее. Так оно подчас воспринимается окружающими и даже самим героем, но Достоевскому-психологу удается показать, как исподволь подготавливалось это «вдруг», «наитие» новых мыслей и чувств. Не «вдруг» принес покаяние Родион Раскольников, не «вдруг» восстала против своих оскорбителей Настасья Филипповна (хотя всем показалось, что именно так), не «вдруг» решил пострадать за «дите» Митя Карамазов» $[6$, с. 166$]$ и т. д. и т. п.

В полной мере это относится и к чуду воскресения Раскольникова в эпилоге романа.

В исследовании Л.М. Розенблюм хорошо показано, что воскресение Раскольникова в эпилоге - это не некое религиозное озарение, а результат, итог и конец долгого пути героя. «Путь этот, несомненно, есть, и начинается он на первых же страницах романа, идет на всем его протяжении, но, так сказать, подспудно, на большей глубине, чем многие другие мысли и чувства, обуревающие Раскольникова. Более того, Раскольников убежден, что ничего подобного с ним не происходит, его сознание противится такому ощущению. И тем не менее и в характере повествования, и в сюжете читатель находит сигналы этого глубинного и нигде прямо не обозначенного процесса возрождения» [6, с. 361-362], пути от «смерти» к «воскресению».

До эпилога наиболее заметными сигналами возможного переворота в душе Раскольникова, предвестиями его духовного воскресения являются следующие.

Как отметили в свое время критики Н. Ахшарумов и И. Анненский, в романе наказание опережает преступление, а не только следует за ним [7, с. 149; 8, с. 191].

Яркий пример тому - сон о забитой лошади, после которого Раскольников взывает к богу: «Господи! - молил он, - покажи мне путь мой, а я отрекаюсь от этой проклятой... мечты моей!» [1, т. 6, с. 50].

В романе Достоевского сны - особенно этот первый и последний, апокалипсический в эпилоге - это знаки глубинного, подсознательного состояния души героя, голос его совести, который он старается заглушить идейной «арифметикой» озлобленного ума (а совесть у Достоевского, по меткому выражению Д. Гранина, «она как бы малое представительство Бога») [9, с. 97]. 
Еще один сигнал того же значения и смысла - обращение Раскольникова к дочери Мармеладова Поле: «Полечка, меня зовут Родион: помолись когда-нибудь и обо мне: «и раба Родиона» - больше ничего» [1, т. 6, с. 147].

Важнейшие вехи на пути возвращения Раскольникова к людям и богу, к его возрождению - эпизоды чтения главы Евангелия о воскрешении Лазаря и покаяния на Сенной площади.

Главу 11 Евангелия от Иоанна - легенду о воскрешении Лазаря - Соня читает Раскольникову по его просьбе. Легенда об исходе воскресшего Лазаря из гроба, ставшего возможным благодаря беззаветной вере сестер умершего Марии и Марфы, прямо перекликается с ситуацией романа, где роль сестер Лазаря выполняет Соня, любовь и страдания которой станут важнейшим фактором воскресения Раскольникова, ставшего на время духовно мертвым [см. об этом: 10, с. 223-224].

Сцене покаяния (пока еще не раскаяния) Раскольникова перед народом на Сенной площади предшествует признание героя Соне в преступлении и ее слова и реакция: «Что делать?.. Встань!.. Поди сейчас, сию же минуту, стань на перекрестке, поклонись, поцелуй сначала землю, которую ты осквернил, а потом поклонись всему свету, на все четыре стороны, и скажи всем вслух: «Я убил!» Тогда Бог опять тебе жизни пошлет» [1, т. 6, с. 322].

«Страдание принять и искупить себя им, вот что надо», - говорит Соня, выражая одну из важнейших мыслей романа о страдании как основе нравственного совершенствования человека.

В романе нашла художественное воплощение важнейшая в мировоззрении Достоевского - писателя и мыслителя философия страдания [11, с. 165-177]. Ее главные положения сформулированы Достоевским в рабочих тетрадях к роману, в заметке под названием «Идея романа»: «Православное воззрение, в чем есть православие». Нет счастья в комфорте, покупается счастье страданием. Таков закон нашей планеты, но это непосредственное сознание, чувствуемое житейским процессом, есть такая великая радость, за которую можно заплатить годами страдания.

Человек не родится для счастья.

Человек заслуживает свое счастье, и всегда страданием.

Тут нет никакой несправедливости, ибо жизненное знание и сознание (т. е. непосредственно чувствуемое телом и духом, т. е. всем жизненным процессом) приобретается опытом pro и contra, которое нужно перетащить на себе» [7, с. 154-155].

В романе мысль эта выражена устами Сони Мармеладовой и Порфирия Петровича, который во время последней встречи - поединка с Раскольниковым говорит: «Я даже вот уверен, что вы «страдание надумаетесь принять»... Потому страданье, Родион Романыч, великая вещь... в страдании есть идея» [1, т. 6, 352].

«К проблематике страдания причастны почти все герои «Преступления и наказания» [11, с. 165], в первую очередь Соня и Раскольников. То, что происходит с героем в финале романа, подготовлено школой страданий, которую он проходит на всем протяжении действия, является итогом мучительной борьбы pro и contra в его душе. Об этом свидетельствуют, помимо всего прочего, слова о Раскольникове следователя Порфирия Петровича: «Ведь понимаю же и я, каково это все перетащить на себе» $[1,6$, с. 344] и Свидригайлова: «А шельма, однако ж, этот Раскольников! Много на себе перетащил» [1, т. 6, с. 390].

В романе исподволь подготавливается перемена в убеждениях Раскольникова. «А вы ведь вашей теории уже не верите» [1, т. 6, с. 352] - проницательно замечает Порфирий Петрович. Справедливость догадки подтверждается ретроспективными размышлениями Раскольникова в эпилоге, незадолго до наметившегося переворота в его убежде- 
ниях: «Он страдал тоже от мысли: зачем он тогда себя не убил? Зачем он стоял тогда над рекой и предпочел явку с повинною?..

Он с мучением задавал себе этот вопрос и не мог понять, что уже и тогда, когда он стоял над рекой, может быть, предчувствовал в себе и в своих убеждениях глубокую ложь. Он не понимал, что это предчувствие могло быть предвестником будущего перелома в жизни его, будущего воскресения его, будущего нового взгляда на жизнь» [1, т. 6, c. 418$]$.

Важно отметить, что не только в шести частях романа, но и в эпилоге Достоевскийхудожник уделяет большое внимание мотивировке духовного воскресения Раскольникова.

Перенесение действия романа из Петербурга, который камнем давил на душу Раскольникова и был соучастником его преступления, продолжающаяся в сознании и душе Раскольникова борьба pro и contra его идеи, смерть матери, вина, которую он не мог не чувствовать, школа каторги, болезнь и апокалиптические сны, в которых ему открывалась вся губительность его идеи-трихины, но уже во вселенском масштабе - все это тоже были веские мотивы, которое в своей совокупности подготовили и обусловили воскресение Раскольникова в финале романа.

В финале «Преступления и наказания» нашли также свое продолжение и завершение два важнейших сюжета романа: Раскольников и народ, Раскольников и Соня. Оба они имеют прямое отношение к судьбе героя и к тому чуду воскресения, которое происходит на последних страницах романа.

Сдержанно-напряженный ритм повествования в эпилоге, его стиль, исполненный «поистине пушкинской простоты и содержательности» [2, с. 101], аналитическое слово Достоевского как художника-психолога, мастерство в изображении новой среды и природы, за которым ощущается жизненный опыт писателя (отбывавшего свой каторжный срок в Омском остроге), - все это тоже придает финалу достоверность и художественную убедительность.

\section{Литература}

1. Достоевский Ф.М. Полн. собр. соч.: в 30 т. - Л., 1972.

2. Карякин Ю.Ф. Достоевский и канун XXI века. - М., 1989.

3. Кожина М.А. Жанр судебной речи в полидискурсивной структуре романа Ф.М. Достоевского «Преступление и наказание» // Вестник Томского государственного университета. - 2011. - № 353. - С. 22-26.

4. Ма Вэньин. Главные герои романа Ф. М. Достоевского «Преступление и наказание» в свете их антропонимов // Наука и школа. - 2014. - № 6. - С. 176-183.

5. Ма Вэньин. Женские образы в романе «Преступление и наказание» (второстепенные героини) в аспектах антропонимики // Перспективы науки. - Тамбов, 2014. № 11. - С. 94-97.

6. Ма Вэньин. Петр Петрович Лужин и его «разумный эгоизм» в романе Ф.М. Достоевского «Преступление и наказание» // Преподаватели XXI века. - М., 2015. - № 2. - С. 399-407.

7. Ма Вэньин. Роман Ф.М. Достоевского «Преступление и наказание» в свете художественной антропонимики (итоги и задачи изучения) // Гуманитарные, социально-экономические и общественные науки. - Краснодар, 2014. - № 1. - С. 372-375.

8. Страхов Н.Н. Литературная критика. - М., 1984.

9. Мережковский Д.С. Л. Толстой и Достоевский. Вечные спутники. - М., 1995.

10. Шкловский В.Б. Повести о прозе. - М., 1996. - Т. 2.

11. Розенблюм Л.М. Творческие дневники Достоевского. - М., 1981. 
12. Ахшарумов H. «Преступление и наказание» // Всемирный труд. -1867 . - № 3.

13. Анненский И. Книги отражений. - М., 1979.

14. Гранин Д. Листопад // Звезда. - 2008. - № 2.

15. Недзвецкий B.A. Русский социально-универсальный роман XIX века. - М., 1997.

16. Тихомиров Б.Н. К вопросу о философии страдания в «Преступлении и наказании» Ф.М. Достоевского // Традиции и новаторство в русской классической литературе. - СПб., 1992.

17. Тихомиров Б.Н. Лазарь! Гряди вон. Роман Ф.М. Достоевского «Преступление и наказание» в современном прочтении». Книга-комментарий. - СПб.: Серебряный век, 2016.

Поступила в редакиฺию 30 ноября 2017 г.

UDC 82

DOI: $10.21779 / 2542-0313-2017-32-4-27-33$

\section{Epilogue as the ending of Fyodor Dostoyevsky's novel «Crime and punishment»}

\section{A.N. Gorbaneva}

Dagestan State University; Russia, 367001, Makhachkala, Gadzhiyev st., 43a; gorbaneva69@mail.ru

The article discusses the place and significance of the epilogue in the ideological struc-ture of Dostoevsky's novel Crime and Punishment. Two of its main functions are revealed.

There are two chapters in the epilogue of Crime and Punishment, the first performs the traditional role of the epilogue, and the second - the function of the denoument completing the conceptual design of the plot of the novel. In this regard, the epilogue is associated with the central problem of the novel: the resurrection of the character comes after crime and punishment and its consequences are attributed by the author to the future beyond the narra-tive making the ending open.

In the process of working on the novel Dostoevsky left other variants of the ending without any implementation (suicide of Raskolnikov, character's 'vision of Christ', remorse after a fire). In the final version the ending fully corresponded to the internal plan of the writ-er, to show the spiritual resurrection of the character.

In the epilogue this happens 'suddenly' as a miracle, but it looks artistically convincing, because it is carefully prepared by the precedent novel.

Keywords: Dostoyevsky, novel ideological structure, epilogue, ending.

Received 30 November, 2017 